\title{
Characteristics and typology of sheep herding systems in the suburban area of Ouagadougou (Burkina Faso)
}

\author{
K. Tindano ${ }^{1}$, N. Moula ${ }^{1,3}$, A. Traoré ${ }^{2}$, P. Leroy ${ }^{1,3}$, and N. Antoine-Moussiaux ${ }^{1,3}$ \\ ${ }^{1}$ Fundamental and Applied Research for Animals \& Health (FARAH), Sustainable Animal Production, Faculty \\ of Veterinary Medicine, University of Liege, 4000 Liege, Belgium \\ ${ }^{2}$ INERA, 04 B.P. 8645, Ouagadougou, Burkina Faso \\ ${ }^{3}$ Tropical Veterinary Institute, Faculty of Veterinary Medicine, University of Liege, 4000 Liege, Belgium
}

Correspondence to: N. Antoine-Moussiaux (nantoine@ulg.ac.be)

Received: 23 July 2015 - Revised: 3 November 2015 - Accepted: 6 November 2015 - Published: 24 November 2015

\begin{abstract}
Strong increase in demand for animal products could benefit local producers in developing countries. This development opportunity particularly concerns suburban livestock. In Burkina Faso, the suburban area of Ouagadougou is a place for the setting up of an increasing number of breeders. Due to its importance in religious traditions, spurring its consumption in whole West Africa, mutton is a major part of this suburban production. In order to characterize sheep farming in the suburban zone of Ouagadougou, in terms of motives, practices, and economic performance, and to better understand the dynamic at play in the sheep sector, a survey has been conducted among 80 sheep farmers around Ouagadougou. The results show that suburban sheep keeping is a highly dual sector. Nearly half $(42.5 \%)$ of farms may be described as traditional livestock, while $50 \%$ are evolving towards intensification. These two groups essentially differ in terms of animal genetic and feeding management, farm infrastructure, and farmer education level. Economically, the whole sample tends to indicate a lack of profitability of the activity in terms of monetary income. Several factors contributing to this situation are pinpointed, namely feed and animal health constraints, flock and production management, and the market conditions.
\end{abstract}

\section{Introduction}

The high demographic and urban growth in developing and emerging countries is accompanied by a strong increase in demand for animal products, of which local producers could benefit (Steinfeld, 2004). Nevertheless, the livestock development programmes in these countries have often involved the use of exotic breeds, for substitution to local stock or for crossbreeding. Also, due to technical and organizational issues, most of these attempts have resulted in failures or shortlived improvements (Madalena et al., 2002; Kosgey et al., 2006). At present, about $70 \%$ of currently existing domestic breeds are found in developing countries but are threatened by complex socio-economic processes pushing for their abandonment, among which the development programmes cited above (Rege and Gibson, 2003; Tisdell, 2003). It is now recognized that the sustainable development of animal husbandry entails the improvement and conservation of indige- nous breeds that show remarkable adaptation to the difficult environments of tropical countries and the low-input systems prevailing in family farming across the world (Kosgey et al., 2006). However, the absence of a clear definition of improvement objectives that would take into account the social and economic specificities of the systems and their ecological constraints have caused the failure of recent efforts to promote indigenous breeds in local development (Kosgey and Okeyo, 2007).

Suburban livestock is more particularly concerned by the development opportunity represented by the rise of demand for animal products (Rischkowsky et al., 2006; Amadou et al., 2012). In Burkina Faso, the suburban area of Ouagadougou is a place for the setting-up of more and more breeders, who could benefit from market proximity, both for products and inputs. Due to its importance in religious traditions, spurring its consumption in whole West Africa, mutton is a major part of this suburban production. This study 


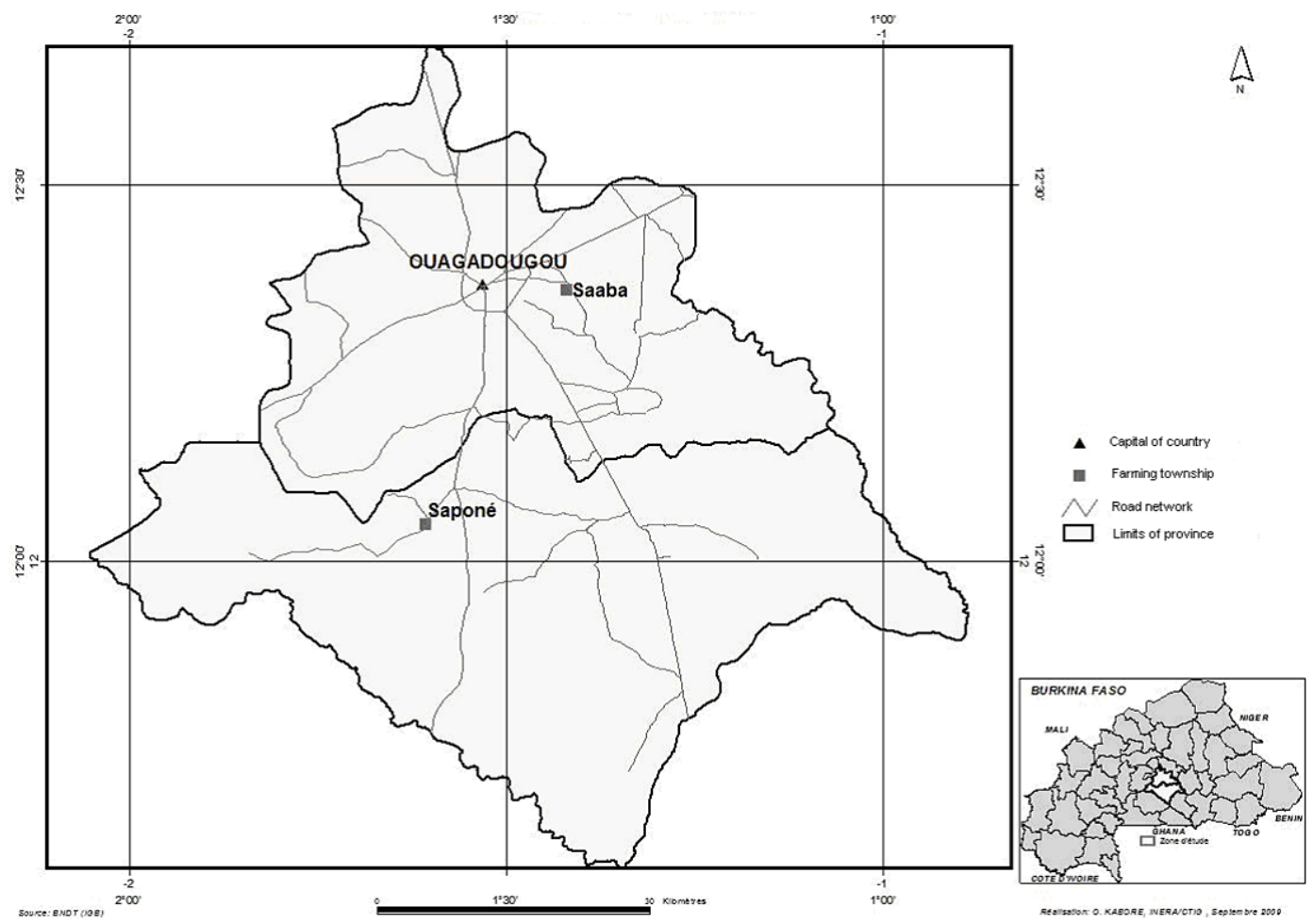

Figure 1. Study area of Ouagadougou, Burkina Faso.

characterizes sheep farming in the suburban zone of Ouagadougou, in terms of motives, practices, and economic performance, to better understand the dynamic at play in the sector. It pays particular attention to sheep genetic resources management. It then draws up a typology of these farms to serve as a basis for future research and development policies.

\section{Material and methods}

\subsection{Overall study design}

First, sheep farms of the suburban area of Ouagadougou were characterized through a survey among 80 farmers, conducted in April and May 2012, with a second passage in April 2014. Second, a 1-year follow-up of economic performances of a sample of 10 farms was conducted from November 2012 to October 2013 (i.e. between the two survey phases).

\subsection{Study area}

Ouagadougou is the largest urban centre in Burkina Faso. It is located in the centre of the country at $12^{\circ} 40 \mathrm{~N}$ latitude and $1^{\circ} 50 \mathrm{~W}$ longitude, with a northern Sudanese climate (Fig. 1). Rainfalls range from 600 to $800 \mathrm{~mm} \mathrm{yr}^{-1}$ and extend from June to October. Vegetation is tree and shrub savanna type with a herbaceous layer, abundant in the rainy season, dominated by species such as Pennisetum, Cenchrus, Aristida and Brachiaria and a ligneous layer dominated by Combretum micranthum, Lannea microcarpa, Vitellaria paradoxa and Parkia biglobosa. Population of Ouagadougou was estimated in 2012 at more than 1915000 inhabitants (INSD, 2014), with more than 187000 sheep.

\subsection{Sampling}

The criterion of inclusion of breeders in the survey was to own a minimum of 10 sheep. In eight zones distributed around the city of Ouagadougou, livestock technicians and key informants were consulted to draw up a list of breeders meeting the above criterion, each including finally from 11 to 26 breeders. For each zone, 10 farmers were drawn randomly for interview.

Herders practising crossbreeding were retained after the passage of 2012 for monitoring of their economic performances. Twenty-four were proposed to be involved in this follow-up. Of the 16 farmers who agreed to begin, 10 cooperated till the end.

\subsection{Data collection}

The questionnaire was applied in face-to-face interviews, in local language. It included multiple choice and open questions. They focused on (i) information on the breeder and the household, (ii) farm infrastructure and flock structure, (iii) breeders' economic activities, (iv) flock management, and (v) breeds and breeding practices. 
The economic monitoring covered data on flock dynamics (stock changes), livestock expenses, and incomes. It was conducted as follows.

- An inventory of the sheep flock was taken at the beginning and the end of monitoring, in which a value was assigned to each animal in agreement with the breeder and taking the market price into account.

- The difference between the value of the flock at the beginning and at the end was counted as income.

- A monthly record of expenses for sheep production was kept: feed, veterinary care, labour, and sheep purchase. For expenses that are common to different species (cattle, sheep, goats), such as feed and labour, all the animals were converted into tropical livestock unit (1 small ruminant $=0.12 \mathrm{TLU}$ ), and the proportion of sheep in the total TLU was applied to expenditures to calculate the share of expenses to be attributed to sheep.

- A monthly record of livestock income was kept: sheep sale as well as home consumption.

The on-farm use of organic manure was not counted as income, considering compensation that occurred between this manure and the own crop residues used for animal feeding, which were then not counted as an expense.

\subsection{Statistical analysis}

All statistical analyses were performed with $\mathrm{R}$ (version 3.0.1). Descriptive statistics, multiple correspondence analysis (MCA) and hierarchical classification analysis (HCA, Ward's algorithm) were performed to establish a typology (package FactoMineR, functions MCA and hierarchical clustering on principle components) (Agro Campus Ouest, Rennes, France). The variables used for MCA and HCA are described in Table 1. Chi-square or Fisher's exact tests were conducted to evaluate the dependence between clusters and categorical variables as well as between categorical variables.

Where data are missing and number of respondents is not equal to 80 , numbers of respondents are mentioned between brackets after citation rates.

\section{Results}

\subsection{Socio-economic characteristics}

Table 2 summarizes socio-economic characteristics of the 80 interviewees and their households. All of them are sedentary, with a very large majority of farms headed by men $(95.0 \%)$. These farm managers are divided mainly into two ethnic groups, namely Mossi $(53.8 \%)$ and Fulani $(38.8 \%)$, with $7.5 \%$ other ethnic groups. Their ages range from 18 to 74 years (mean 43.1 ). In terms of education, $31.3 \%$ of herders have not received any formal education, while $18.8 \%$ have a university level. The main motives to be involved in livestock are profit (income, additional income) in $41.3 \%$ of cases and intangible satisfaction (culture, passion for breeding, conservation of heritage) in $58.8 \%$ of cases. The education level and motives to be involved in livestock show a statistically highly significant dependence (Fisher's exact test, $p<0.0001$ ), with high levels of education associated with purely economic motives. In $81.2 \%$ of households, at least one family member works on the farm and $46.2 \%$ of farms use hired non-family labour.

Sheep flocks range from 10 to 102 animals per farm, with a median and third quartile equal to 21 and 36.5, respectively. All interviewees have other economic activities. Sheep are mainly kept as a second or third economic activity. Sheep production is then combined with other agricultural activities such as food crops $(96.2 \%)$, other livestock species $(87.5 \%)$, and cash crops $(17.5 \%)$. Nearly half of respondents $(48.0 \%$, 37 on 77 respondents) have non-agricultural economic activities. Among them, $40.5 \%$ are employees, $37.8 \%$ traders, and $21.6 \%$ divided in modalities as craftsmen or retired.

Investments in sheep keeping are made with own savings. Interviewees justify this situation by insufficient information on conditions of access to credit, a too high risk of credit, or the unfavourable loan conditions proposed by financial institutions. Access to livestock markets is not presented as a constraint. About $36 \%$ (28 on 77 respondents) of farmers have contacts with livestock traders, buying animals at farm gate. Others operate a choice between several markets and consider that there are always buyers at prices that satisfy them. However, $5.2 \%$ (4 on 77 respondents) of farmers report unfavourable market evolutions in recent years, due to an increase in feed costs, which strongly reduces profit margins.

\subsection{Production management}

Common pastures are exploited by $86.5 \%$ (64 on 74 respondents) of farmers, and $64.1 \%$ of them leave their flock freely grazing there during the dry season. Zero grazing is practised by $13.5 \%$ of farmers (10 on 74 respondents). All farmers distribute supplementary feeding, composed of concentrates $(92.5 \%)$ and/or roughages $(96.2 \%)$. This supplement is distributed all year round $(30.0 \%)$, only during the dry season $(62.5 \%)$, or part of the dry season $(7.5 \%)$. Feed scarcity is cited as part of the constraints on production. The drinking water comes from different sources: drill holes $(53.7 \%)$, tap $(23.7 \%)$, water impoundments $(15.0 \%)$, ponds $(5.0 \%)$, and wells $(2.5 \%)$. The types of shelter for sheep include pens with roof $(47.5 \%)$ and roofless pens $(43.7 \%)$. The others do not have any infrastructure to house their animals. 
Table 1. Codes for variables and modalities used in multiple correspondence analysis.

\begin{tabular}{|c|c|c|}
\hline Variables & Codes & Modalities \\
\hline Education & Educat & $\begin{array}{l}\text { educat } 1 \text { : no formal education } \\
\text { educat2: primary or secondary } \\
\text { educat3: higher education }\end{array}$ \\
\hline Breeding objectives & object & $\begin{array}{l}\text { object } 0 \text { : no selection } \\
\text { object } 1 \text { : young's growth/weight } \\
\text { object2: rusticity }\end{array}$ \\
\hline Reasons for involvement in livestock & reason & $\begin{array}{l}\text { reason 1: farmers with purely economic objectives (generating cash income) } \\
\text { reason2: farmers having other reasons in addition to economic goals }\end{array}$ \\
\hline Breeds & breeds & $\begin{array}{l}\text { breed1: Djallonké pure breed } \\
\text { breed2: presence of crossbreed or Fulani pure breed }\end{array}$ \\
\hline Non-agricultural economic activity & econact & $\begin{array}{l}\text { econact } 0: \text { no } \\
\text { econact } 1: \text { yes }\end{array}$ \\
\hline Concentrate distribution period & concep & $\begin{array}{l}\text { conce } 0 \text { : no concentrate } \\
\text { conce 1: concentrate all year } \\
\text { conce 2: concentrate all dry season } \\
\text { conce3: concentrate only part of the dry season }\end{array}$ \\
\hline Systematic deworming & deworm & $\begin{array}{l}\text { deworm0: no } \\
\text { deworm1: yes }\end{array}$ \\
\hline Ethnicity of breeder & ethnic & $\begin{array}{l}\text { mossi: Mossi herder } \\
\text { fulani: Fulani herder } \\
\text { other3: other ethnic herder }\end{array}$ \\
\hline Type of fold & fold & $\begin{array}{l}\text { fold1: no enclosure } \\
\text { fold2: enclosure without roof } \\
\text { fold3: enclosure with roof }\end{array}$ \\
\hline Number of sheep & number & $\begin{array}{l}\text { number } 1 \text { : number of sheep }<30 \\
\text { number } 2 \text { : number of sheep between } 30 \text { and } 50 \\
\text { number } 3 \text { : number of sheep }>50\end{array}$ \\
\hline
\end{tabular}

\subsection{Health}

Flocks are monitored by a technician in $75.0 \%$ of cases, and $78.7 \%$ of flocks are regularly dewormed and vaccinated for pasteurellosis. In case of disease, $80.0 \%$ of farmers call an animal health technician. Self-medication is, however, also practised by $52.5 \%$ of farmers. Veterinary drugs are bought from animal health technicians $(71.2 \%)$, veterinary pharmacies $(22.5 \%)$, and in local markets $(22.5 \%)$. The average distance of farms to veterinary structure is $5.60 \pm 3.87 \mathrm{~km}$. This distance is not significantly linked to the practice of selfmedication $(p=0.29)$. The most cited conditions are diarrhoea $(71.2 \%$ citation rate), pulmonary disorders $(68.7 \%)$, lameness $(15.0 \%)$, and loss of appetite $(11.2 \%)$. Overall, these conditions are identified as a major constraint as they strongly influence production.

\subsection{Animal genetic resources}

Sheep genetic resources consist mostly of three populations: the Mossi Djallonké sheep (representing $74.5 \%$ of the sampled flocks), Fulani sheep (6.1\%), and crossbreeds of these two breeds (19.4\%). Generally, the Mossi sheep is described in the interviews as a prolific and disease-resistant breed, well adapted to its environment but with a slow growth and low adult weight. The Fulani breed is subject to the reverse description, i.e. showing good growth and good adult weight but low resistance to diseases due to a poor adaptation to the environment. The crossbreeds are described as having intermediate characteristics. Among producers keeping several breeds or genetic types ( $33.7 \%$ of the surveyed farmers), $74.1 \%$ state a preference for crossbreeds thought to represent a good compromise between resistance and growth. Pure Fulani sheep is preferred by $25.9 \%$ of interviewees for its higher weight and market price.

\subsection{Reproduction and genetic improvement}

An active selection of breeding rams is stated by $82.5 \%$ of interviewees, while only $12.5 \%$ select breeding females. Breeding stock selection is mainly made in own flock $(63.7 \%)$ and may be bought from neighbouring breeders or at the market place (58.7\%). Unselected males are sold but can remain in the flock to wait for a favourable period or liquidity needs requiring a sale. They do not practise castration and there are no other means to control mating, $88.7 \%$ of breeders relying on the dominant behaviour of their breeding male, even during the period of free grazing. 
Table 2. Socio-economic characteristics.

\begin{tabular}{|c|c|c|}
\hline Variables & $\begin{array}{r}\text { Breeders' } \\
\text { percentages }(\%)\end{array}$ & Means and SD \\
\hline \multicolumn{3}{|l|}{ Sex } \\
\hline Male & 95.00 & - \\
\hline Female & 5.00 & - \\
\hline \multicolumn{3}{|l|}{ Ethnic group } \\
\hline Mossi & 53.75 & - \\
\hline Fulani & 38.75 & - \\
\hline Other ethnic & 7.50 & - \\
\hline \multicolumn{3}{|l|}{ Instruction level } \\
\hline No instruction & 31.25 & - \\
\hline Koranic school & 13.75 & - \\
\hline Local language literate & 6.25 & - \\
\hline Primary school & 17.50 & - \\
\hline Secondary school & 12.50 & - \\
\hline University & 18.75 & - \\
\hline \multicolumn{3}{|l|}{ Marital status } \\
\hline Single & 3.75 & - \\
\hline Widower & 3.75 & - \\
\hline Monogamous married & 62.50 & - \\
\hline Polygamous married & 23.75 & - \\
\hline \multicolumn{3}{|l|}{ Herding reasons } \\
\hline Tangible benefit & 41.25 & - \\
\hline Intangible benefit & 58.75 & - \\
\hline \multicolumn{3}{|l|}{ Other economic activity } \\
\hline Agricultural & 100.00 & - \\
\hline Non-agricultural & 48.05 & - \\
\hline Breeders' age & - & $46.13 \pm 12.69$ \\
\hline Household size & - & $8.80 \pm 5.02$ \\
\hline \multicolumn{3}{|l|}{ Herds or flock } \\
\hline Sheep & 100.00 & $26.56 \pm 18.55$ \\
\hline Cattle & 76.25 & $28.82 \pm 20.14$ \\
\hline Goat & 60.00 & $18.36 \pm 13.10$ \\
\hline Pig & 5.00 & $17.33 \pm 11.01$ \\
\hline
\end{tabular}

Selection objectives focus mainly on improving adult weight $(87.9 \%)$, growth speed $(83.3 \%)$, and rusticity $(54.5 \%)$. Selection criteria are adult body size $(68.2 \%$ citation), conformation (39.4\%), coat colour (22.7\%), rusticity $(21.2 \%)$, and growth (13.6\%). Choice is mainly based on own performance ( $100 \%$ of farmers) and performance of ascendants $(54.5 \%)$. They do not weigh their animals. Thus, both growth and weight are judged visually.

\subsection{Economic performances}

On the 10 farms monitored, 7 (numbers 01 to 07 in Table 3) have a positive average annual income of FCFA (Franc de la Communauté Financière Africaine) $4494 \pm 2682$ per sheep (EUR $\sim 6.85 \pm 4.10$ ) and the 3 remaining operate with an average annual loss of FCFA $8224 \pm 12617$ per sheep (EUR $\sim 12.54 \pm 19.24$ ). Table 3 presents an estimate of the revenue generated during the year as well as the different costs of production for the 10 producers. Two breeders (numbers 09 and 10 in Table 3) who operated at a loss had the particularity to employ both a shepherd and a supervisor. The

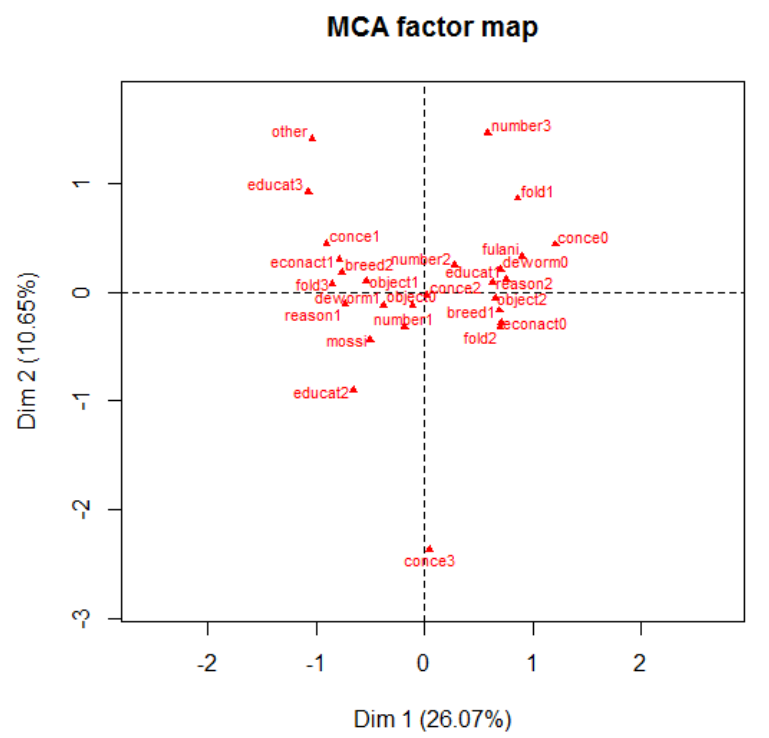

Figure 2. Graphic representation of modalities on axis 1 and 2 (see Table 1 for signification of codes).

third (number 08 in Table 3) maintains his animals in permanent stalling but without maintaining a stock of feed (feed is thus paid daily).

\subsection{Typology}

\subsubsection{Multiple correspondence analysis}

Multiple correspondence analysis, applied to 10 variables with 27 modalities, allowed discriminating these modalities following three selected factors, representing $45.2 \%$ of total variability. Table 4 shows the statistical link between these variables and the first three axes, as estimated through analysis of variance.

Axis 1 (Fig. 2) opposes modalities tied to intensification (concentrate feeding, deworming crossbreeding, permanent infrastructure) (negative coefficients on the axis) to those tied to extensive herding (positive coefficients). The former group of modalities describing intensification is associated with Mossi ethnic group (or other non-Fulani breeders) with a high level of education, having another economic activity, and small flock sizes. The latter group of modalities describing a lack of intensification is associated with Fulani ethnic group, large flock sizes, and low education levels.

Axis 2 is correlated to the supplementation strategy in association with the level of education (Fig. 2). Concentrate feed distribution for only part of the dry season and primary/secondary education have shown negative coefficients. Positive coefficients are ascribed to concentrate feed distribution throughout the year and high education level breeders.

Axis 3 describes the use of genetic resources (Fig. 3). It opposes the lack of selection in midsize flock and breeders with a high level of education (negative coefficients) to se- 
Table 3. Costs, returns, and margin in FCFA for 10 breeders.

\begin{tabular}{lrrrrrrr}
\hline $\begin{array}{l}\text { Farm } \\
\text { number }\end{array}$ & $\begin{array}{r}\text { Returns per } \\
\text { sheep }\end{array}$ & $\begin{array}{r}\text { Animal } \\
\text { purchase } \\
\text { cost per sheep }\end{array}$ & $\begin{array}{r}\text { Feeding } \\
\text { cost per sheep }\end{array}$ & $\begin{array}{r}\text { Veterinary } \\
\text { cost per sheep }\end{array}$ & $\begin{array}{r}\text { Labour } \\
\text { cost per sheep }\end{array}$ & $\begin{array}{r}\text { Total } \\
\text { cost per sheep }\end{array}$ & $\begin{array}{r}\text { Margin per } \\
\text { sheep }\end{array}$ \\
\hline 01 & 11333.33 & 0 & 5873.33 & 983.33 & 0 & 6856.67 & 4476.67 \\
02 & 10409.84 & 0 & 245.9 & 754.1 & 1475.41 & 2475.41 & 7934.43 \\
03 & 5670.73 & 0 & 853.66 & 951.22 & 3048.78 & 4853.66 & 817.07 \\
04 & 6074.07 & 0 & 1022.22 & 851.85 & 0 & 1874.07 & 4200 \\
05 & 12961.54 & 2461.54 & 1000 & 961.54 & 0 & 4423.08 & 8538.46 \\
06 & 8000 & 0 & 1720.91 & 1022.73 & 3613.64 & 6357.27 & 1642.73 \\
07 & 9661.29 & 0 & 1669.03 & 951.61 & 3190.97 & 5811.61 & 3849.68 \\
08 & 19062.5 & 18125 & 21825 & 1875 & 0 & 41825 & -22762.5 \\
09 & 4657.14 & 0 & 948.57 & 1068.57 & 4405.71 & 6422.86 & -1765.71 \\
10 & 6270.83 & 0 & 1520.83 & 1518.75 & 3375 & 6414.58 & -143.75 \\
\hline
\end{tabular}

lection for improvement of rusticity in large flock size among breeders with a secondary or primary level (in positive coefficients).

\subsubsection{Hierarchical classification and clusters' description}

The hierarchical cluster analysis was performed on all variables. Three groups were retained, conserving a variance between groups of $68.6 \%$ of the total variability. Figure 4 shows the three groups of farmers. Table 5 shows the percentages of the most significant modalities in the three clusters, and Table 6 shows the distribution of farmers in these clusters by modalities.

Cluster 1 (34 farmers, $42.5 \%$ of total) can be described as traditional livestock keepers. It is best described by modalities with positive coefficients on axis 1 , as presented above (extensive herding).

Cluster 2 (6 farmers, $7.5 \%$ of total) is composed of Mossi breeders (100\%), holding Mossi sheep (100\%), and using feed supplementation during only part of the dry season (100\% of individuals).

Cluster 3 (40 farmers, $50 \%$ of total) consists of intensive farming systems, best described by the modalities with negative coefficients on axis 1 (intensification) (Fig. 2).

Statistical link with the cluster variable is highly significant $(p<0.001)$ for the following variables: breeds, education level, supplementation period, ethnic group, main motive for livestock keeping, practice of a non-agricultural economic activity, type of enclosure, and systematic deworming. This link is highly significant for selection objectives $(p<0.01)$ and significant for flock size $(p<0.05)$.

\section{Discussion}

\subsection{Socio-economic characterization}

Men predominance in the present sample of sheep breeders in the suburban area of Ouagadougou is in agreement with

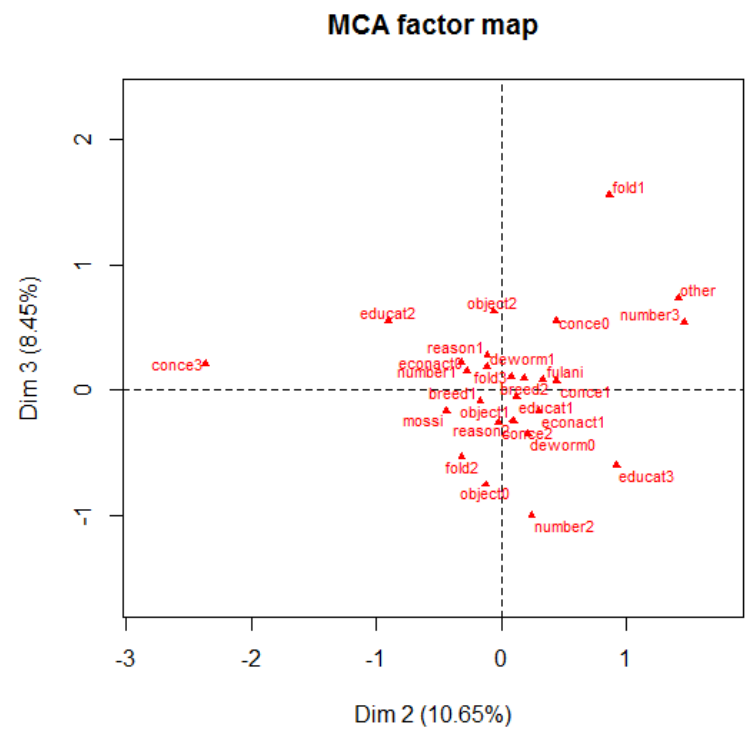

Figure 3. Graphic representation of modalities on axis 2 and 3 (see Table 1 for signification of codes).

that already found for urban livestock keepers $(91.5 \%$, all livestock species) in the same city (Thys et al., 2005). Predominance of Mossi breeders is also found by Kaboré et al. (2011) for the same area, although with different proportions (respectively, 73.3, 26.6, and $0 \%$ ). The present typology shows that ethnic groups tend to have different practices. The proportion of breeders without a formal education $(51.3 \%)$ and that of high education level $(18.8 \%)$ are both much higher than those found in the more strictly urban areas of Ouagadougou by Thys et al. (2005) (39.7 and 6.4\%, respectively). These differences may reflect on the one hand the higher presence of people with a low educational level in the suburbs (coming from rural areas or pushed away from the city by rising costs of living) and on the other hand the investment of city dwellers with higher education level and higher living standards in suburban farms. Therefore, the suburban 
Factor map

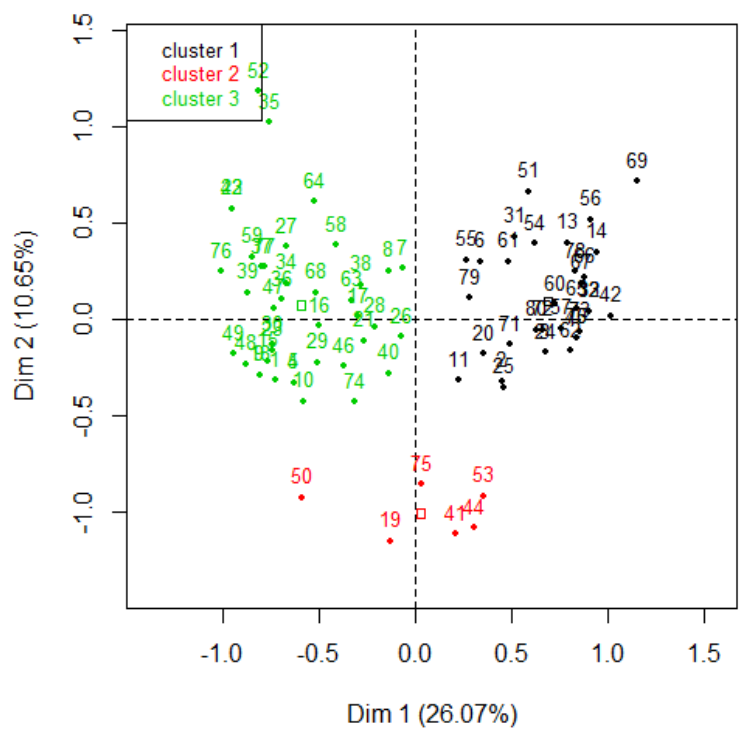

Figure 4. Graphic representation clusters on axis 1 and 2 (the numbers correspond to breeders' identifiers).

Table 4. Degrees of statistic link between variables and the three first axes.

\begin{tabular}{llll}
\hline Variables & Dim1 & $\operatorname{Dim} 2$ & $\operatorname{Dim} 3$ \\
\hline educat & $* * *$ & $* * *$ & $*$ \\
fold & $* * *$ & $*$ & $* * *$ \\
econact & $* * *$ & $*$ & - \\
breeds & $* * *$ & - & - \\
ethnic & $* * *$ & $* * *$ & \\
reason & $* * *$ & - & $*$ \\
concep & $* * *$ & $* * *$ & - \\
deworm & $* * *$ & - & $*$ \\
object & $* * *$ & - & $* * *$ \\
number & $*$ & $* * *$ & $* * *$ \\
\hline
\end{tabular}

$* p$ value $<0.05, * * * p$ value $<0.001,-$ : lack of link.

sheep keeping appears as a highly dual sector. The typology confirms this tendency with two major clusters (1 and 3), grouping $92.5 \%$ of the sample. These analyses show that breeders with low levels of education are mainly in a cluster conserving traditional practices and holding larger flocks (cluster 1) while those with a higher level are grouped in the cluster of intensive farming with smaller flocks (cluster 3). This points to a possible direct impact of education on the adoption of innovations or to an indirect effect of the better living standards (Ajala et al., 2008).

Sheep keeping in the present study area is mainly a secondary economic activity, as for example in the suburbs of Maroua (Cameroon) where only $22 \%$ of interviewees hold sheep as their main activity (Rischkowsky et al., 2006). Sheep keeping is thus integrated mainly to other agricul-
Table 5. Distribution of breeders in clusters for the most relevant modalities.

\begin{tabular}{llll}
\hline Modalities & Cluster 1 & Cluster 2 & Cluster 3 \\
\hline educat1 & 94.1 & - & - \\
fulani & 79.4 & - & - \\
reason2 & 91.2 & - & - \\
econact0 & 88.2 & - & - \\
breed1 & 88.2 & 100 & - \\
fold2 & 70.6 & - & - \\
deworm0 & 61.8 & - & - \\
object2 & 64.7 & - & - \\
conce3 & - & 100 & - \\
object1 & - & - & 62.5 \\
deworm1 & - & - & 87.5 \\
Mossi & - & 100 & 75 \\
econact1 & - & - & 82.5 \\
breed2 & - & - & 85 \\
fold3 & - & - & 80 \\
reason1 & - & - & 75 \\
\hline
\end{tabular}

“-” indicates low percentages.

Table 6. Distribution of farmers in the three clusters by modality.

\begin{tabular}{lrrrr}
\hline Modalities & Cluster 1 & Cluster 2 & Cluster 3 & Total \\
\hline educat1 & 32 & 2 & 8 & 42 \\
educat2 & 2 & 4 & 16 & 22 \\
educat3 & 0 & 0 & 16 & 16 \\
object0 & 4 & 2 & 8 & 14 \\
object1 & 8 & 2 & 25 & 35 \\
object2 & 22 & 2 & 7 & 31 \\
reason1 & 3 & 4 & 30 & 37 \\
reason2 & 31 & 2 & 10 & 43 \\
breed1 & 30 & 6 & 6 & 42 \\
breed2 & 4 & 0 & 34 & 38 \\
econact0 & 30 & 5 & 7 & 42 \\
econact1 & 4 & 1 & 33 & 38 \\
conce0 & 14 & 0 & 0 & 14 \\
conce1 & 1 & 0 & 19 & 20 \\
conce2 & 19 & 0 & 21 & 40 \\
conce3 & 0 & 6 & 0 & 6 \\
deworm0 & 21 & 2 & 5 & 28 \\
deworm1 & 13 & 4 & 35 & 52 \\
fulani & 27 & 0 & 4 & 31 \\
mossi & 7 & 6 & 30 & 43 \\
other & 0 & 0 & 6 & 6 \\
fold1 & 7 & 0 & 2 & 9 \\
fold2 & 24 & 4 & 6 & 34 \\
fold3 & 3 & 2 & 32 & 37 \\
number1 & 17 & 6 & 31 & 54 \\
number2 & 10 & 0 & 7 & 17 \\
number3 & 7 & 0 & 2 & 9 \\
\hline & & & &
\end{tabular}

tural activities and other livestock species such as cattle, goats, or chickens. Therefore, sheep keeping in the suburbs 
of Ouagadougou is mostly part of a strategy of diversification and does not appear to local stakeholders as a potential area of specialization. Similar observations have been made in Bobo-Dioulasso (Dossa et al., 2015).

\subsection{Objectives of suburban sheep farming and profitability}

At first glance, the market seems to be favourable to the production, with only $5.2 \%$ of interviewees unsatisfied with the market price. However, open discussions could shed a different light on this overall statement. Indeed, it appears in narratives that what satisfies the majority is the financial role of sheep that allows saving small amounts daily through feeding and then recovering an important amount when needed, to pay children's schooling, health care, or to buy goods or other animals (cattle). However, many farmers are aware that if they took all expenses into account in setting the price, they would not find any buyer. Therefore, they are well conscious of the cost of this savings mode. For some breeders, the value compensating for the lack of profitability is cultural. For others, this is explained by the total lack of access to other savings services. As expressed, the most important is for them to immobilize the money to be sure that it will not be spent. Banerjee and Duflo (2007) explain how the awareness of self-control problems pushes poor people to develop stringent and costly savings strategies.

Although the small sample monitored and the non-random selection of it do not allow inferring on the situation of the whole suburban sheep production, the economic follow-up of 10 voluntary farmers corroborates the poor or inexistent profitability of this activity. Indeed, although positive, the present results do not take into account the opportunity costs of labour or land. Several factors contributing to this situation may be pinpointed. First, management issues can be listed, as for example too numerous hired workers, the lack of stock for feed, or the practice of zero grazing. Then, the role of sheep as savings delays their sales beyond ages of profitable feed conversion index or even beyond growth. Feed thus represents in these cases an unproductive expenditure. Moreover, prices between farm gate and end consumers are multiplied by only 1.2 to 1.9 following the sector, these same factors ranging from 5 to 8 in Europe (Renard, 2003). The low overall purchasing power of consumers pushes down prices, as those will not seek to satisfy a quantitative need but rather devote a relatively constant budget for the purchase of animal products (Hoffmann and Bernhard, 2007; Renard, 2003). Finally, diseases and mortality further strain the profitability of sheep keeping and make it more risky, discouraging own investments and attribution of credits by financial institutions.

Nevertheless, while analysing this apparent lack of profitability, one should keep in mind that the present calculations have neglected the true multifunctionality of the animals - which is to take them into account to evaluate the final profit combining monetary and non-monetary incomes
(Ayalew et al., 2003). Therefore, if the financial services provided by sheep were to value, as well as their social and cultural benefits, these could result in a positive outcome clearly explaining the maintenance of the activity in the area.

\subsection{Feed and health}

Feeding system as well as the practice of free grazing in our sample is similar to the practices found in the suburbs of Maroua, Cameroon (Rischkowsky et al., 2006). Complementation strategy is the factor that distinguishes cluster 2 , with a distribution for only part of the dry season. This way of complementation is primarily directed towards risk management, while in cluster 3 (supplementation all year) strategy is more oriented towards production. These strategies resemble those observed by Zoundi et al. (2003) in Burkina Faso's rural area.

Rate of self-medication observed among farmers (52.5\%) and lack of influence of distance from the farm to the nearest veterinary infrastructure on this practice show that proximity of veterinary services is not well exploited. The main diseases encountered in the area correspond to what is reported by Kaboré et al. (2011) for small ruminant livestock in the same study area.

\subsection{Animal genetic resources}

Breeders' perception of the different breeds is consistent with scientific literature, describing the better growth and weight for the Fulani sheep compared to the Djallonké (Gnanda et al., 2005) and the good adaptation and better resistance to diseases of the Djallonké compared to Fulani sheep (Bengaly et al., 1993). Farmers consider that the crossbred is a good compromise between these different qualities. The presence of these three genetic types is also observed in urban livestock in Bobo-Dioulasso (Burkina Faso) (Dossa et al., 2015).

Generally, breeders who cited rusticity as a selection criterion belong to the more traditional cluster 1 and hold the Djallonké breed. This is consistent with the savings objective and may also reflect a greater aversion to risk of this category of breeders. According to these breeders, the rusticity of their animals makes unnecessary the use of deworming and allows them to operate without veterinary support. Cluster 3 breeders show more enthusiasm for sheep of larger size. They select animals on that criterion and also make use of crossbreeding. These farmers have other secure sources of income, which might be interpreted as allowing them to take more risks in their farming activity. However, some sheep owners in this cluster do not make use of any selective breeding, due to their lack of time to devote to this, or due to their insufficient experience, as they began the activity recently. Crossbreeding was practised without any willingness to control the percentage of Fulani blood in their flock. Hence, crossbred females are further mated with Fulani males, which leads rapidly to less-adapted genetic types. So far, crossbreeding involves only local breeds, no use of 
exotic breeds being identified in our investigation. This situation can be explained by the lack of extension services for artificial insemination in small ruminants and the high costs attached to the import and keeping of exotic breeding males in Burkina Faso.

If a large majority of breeders select their breeding males, breeding conditions (particularly animals freely grazing) are not favourable to mating control. Indeed, if the reliance on the dominance of a selected male can be effective within the flock (because it is usually the strongest), this is no longer checked when flocks come together.

\section{Conclusion}

On the whole, sheep farming in the suburban area of Ouagadougou is a secondary economic activity with little intensification. Classic constraints, i.e. feed cost and poor access to health care, together with deep management problems tied to the savings role of sheep, make this activity economically unprofitable. The sector appears nevertheless dual, with a traditional sector and a more recent one driven by new players consisting of city dwellers investing in suburban farming. These new players benefit from higher levels of education and higher living standards. They are more sensitive to growth criteria in the management of their sheep genetic resources but lack a true business orientation of the activity. The added value of crossbreeds as a compromise between rusticity and growth is well understood. However, the levels of each parental breed are not controlled, and a drift towards Fulani breed is observed. Therefore, the present development of the sector does not appear sustainable and calls for a framework to accompany breeders in the management of their farm and their genetic resources regarding their respective goals.

Acknowledgements. We would like to thank WBI for their financial support.

Edited by: S. Maak

Reviewed by: S. Erat and A. Yilmaz

\section{References}

Ajala, M. K., Lamidi, O. S., and Otaru, S. M.: Peri-urban small ruminant production in northern guinea savanna, Nigeria, Asian J. Anim. Vet. Adv., 3, 138-146, 2008.

Amadou, H., Dossa, L. H., Lompo, D. J. P., Abdulkadir, A., and Schlecht, E.: A comparison between urban livestock production strategies in Burkina Faso, Mali and Nigeria in West Africa, Trop. Anim. Health Pro., 44, 1631-1642, 2012.

Ayalew, W., King, J. M., Bruns, E., and Rischkowsky, B.: Economic evaluation of smallholder subsistence livestock production: lessons from an Ethiopian goat development program, Ecol. Econ., 45, 473-485, 2003.

Banerjee, A. V. and Duflo, E.: The economic lives of the poor, J. Econ. Perspect., 21, 141-167, 2007.
Bengaly, Z., Clausen, P. H., Boly, H., Kanwe, A., and Duvallet, G.: Comparaison de la trypanosomose expérimentale chez certaines races de petits ruminants au Burkina Faso, Revue Elev. Méd. vét. Pays trop., 46, 563-570, 1993.

Dossa, L. H., Sangaré, M., Buerkert, A., and Schlecht, E.: Production objectives and breeding practices of urban goat and sheep keepers in West Africa: regional analysis and implications for the development of supportive breeding programs, SpringerPlus, 4, 1-12, doi:10.1186/s40064-015-1075-7, 2015.

Gnanda, I. B., Nianogo, A. J., Zoundi, J. S., Somda, J., and Koanda, S.: Performances techniques et économiques de l'embouche ovine en exploitation traditionnelle de la région sahélienne au Burkina Faso, Rev. CAMES-Série A, 3, 49-56, 2005.

Hoffmann, I. and Bernhard, J.: Meat marketing in Burkina Faso after the devaluation of the FCFA: Insights into the functioning of informal market systems, Food Policy, 32, 229-245 2007.

INSD: available at: http://www.insd.bf/n/ (last access: 18 November 2015), 2014.

Kaboré, A., Traoré, A., Gnanda B. I., Nignan, M., Tamboura, H. H., and Belem, A. M. G.: Constraints of small ruminant production among farming systems in periurban area of Ouagadougou, Burkina Faso (West Africa), Adv. Appl. Sci. Res., 2, 588-594, 2011.

Kosgey, I. S. and Okeyo, A. M.: Genetic improvement of small ruminants in low-input, smallholder production systems: Technical and infrastructural issues, Small Ruminant Res., 70, 76-88, 2007.

Kosgey, I. S., Baker, R. L., Udo, H. M. J., and Van Arendonk, J. A. M.: Successes and failures of small ruminant breeding programmes in the tropics: a review, Small Ruminant Res., 61, 1328, 2006.

Madalena, F. E., Agyemang K., Cardellino, R. C., and Jain, G. L.: Genetic improvement in medium-to low-input systems of animal production. Experiences to date, 7th World Congress on Genetic Applied to Livestock Production, 19-23 August 2002, Montpellier, France, 10 pp., 2002.

Rege, J. E. O. and Gibson, J. P.: Animal genetic resources and economic development: issues in relation to economic valuation, Ecol. Econ., 45, 319-330, 2003.

Renard, J. F.: Filières de commercialisation et pauvreté: le cas des produits animaux au Burkina Faso, in: Elevage et pauvreté, acte de l'atelier CIRAD, Montpellier, 11-12 September 2003, edited by: Duteurtre, G. and Faye, B., CIRAD, Montpellier, France, 200 pp., 2003.

Rischkowsky, B., Bednarz, K., and Jahn, G.: Peri-urban sheep production in West Africa: Do smallholders benefit from proximity of the urban centres?, Small Ruminant Res., 66, 22-31, 2006.

Steinfeld, H.: The livestock revolution - a global veterinary mission, Vet. Parasitol., 125, 19-41, 2004.

Thys, E., Oueadraogo, M., Speybroeck, N., and Geerts, S.: Socioeconomic determinants of urban household livestock keeping in semi-arid Western Africa, J. Arid Environ., 63, 475-496, 2005.

Tisdell, C.: Socioeconomic causes of loss of animal genetic diversity: analysis and assessment, Ecol. Econ, 45, 365-376, 2003.

Zoundi, J. S., Sawadogo, L., and Nianogo, A. J.: Pratiques et stratégies paysannes en matière de complémentation des ruminants au sein des systèmes d'exploitation mixte agriculture-élevage du plateau central et du Nord du Burkina Faso, Tropicultura, 21, 122-128, 2003. 